\title{
Pedagogías para la reconciliación: prácticas artísticas para hacer las paces en Colombia
}

\author{
Pedagogies for Reconciliation: \\ Artistic Practices for Peacemaking in Colombia
}

Josefina Echavarría-Álvarez (D) https://orcid.org/0000-0001-5637-5942

Universidad de Innsbruck, Austria y Universidad de Notre Dame, Estados Unidos

josefina.echavarria@uibk.ac.at

Recepción:

05/07/19

Aprobación:

29/10/19

Palabras clave: Colombia, post-acuerdo, reconciliación, Filosofía para Hacer las Paces, artes, pedagogía, transformación de conflictos. de fotografía El Testigo de Jesús Abad Colorado, los documentales de Daniela Abad Lombana y la Asociación Más Arte Más Paz. Los resultados de investigación ponen de manifiesto claves para las pedagogías de reconciliación para hacer las paces en el post-acuerdo colombiano.

\begin{abstract}
In the face of the challenges to the implementation of the Final Agreement between the Colombian government and the guerrillas FARC-EP, artistic practices give life to peacebuilding and reconciliation, constituting key elements for the pedagogies for reconciliation. It starts with a literature review on peace research proposals that highlight the Philosophy for Peace and the capacities of individuals and communities to reconcile in plural and diverse ways. Afterwards, the article discusses the institutional architecture of the Transitional Justice System, with emphasis on the Truth Commission. Finally, the text shows three qualitative research examples of auto-ethnography, semi-structured interview and focus groups about the photography exhibition The Witness (El Testigo) by Jesús Abad Colorado, the documentary films of Daniela Abad Lombana and the Association More Art More Peace (Más Arte Más Paz). The research results serve to draw key findings regarding the pedagogies for reconciliation in the Colombian postaccord context.
\end{abstract}

Key words: Colombia, Post-Agreement, Reconciliation, Philosophy for Peace, Arts, Pedagogy, Conflict Transformation.

Resumen: En medio de los retos para implementar el Acuerdo Final entre el gobierno colombiano y la guerrilla de las FARC-EP, prácticas artísticas dan vida a la construcción de paz y reconciliación, conformando elementos clave de las pedagogías para la reconciliación. El texto comienza con una revisión de literatura de en la Investigación para la Paz resaltando la Filosofía para hacer las Paces y las capacidades de individuos y comunidades para reconciliarse. Luego se discute la arquitectura del Sistema de Justicia Transicional, con énfasis en la Comisión para la Verdad. Finalmente, el texto presenta tres ejemplos cualitativos de investigación autoetnográfica, entrevista semiestructurada y grupos de enfoque sobre la exposición 


\section{Introducción $^{1}$}

En noviembre de 2016, el Congreso colombiano aprobó el Acuerdo Final para la Terminación del Conflicto y la Construcción de una Paz Estable y Duradera (Acuerdo Final, 2016) entre el gobierno y las guerrillas Fuerzas Armadas Revolucionarias de Colombia-Ejército del Pueblo (FARC-EP), el cual buscaba culminar una guerra escalofriante de más de cinco décadas, ocho millones de víctimas y cerca de 220.000 asesinatos (CNMH, 2013). A pesar de que el Acuerdo Final fue apoyado por la comunidad internacional, calificado como uno de los más completos del mundo y con alta participación de la sociedad civil, especialmente de las víctimas (Bouvier, 2014; Peace Insight, 2017), la implementación del Acuerdo ha estado sometida a un sinnúmero de obstáculos (Kroc, 2018). ${ }^{2}$ Entre estos se cuentan los obstáculos políticos, desde la elección en junio de 2018 del presidente Iván Duque, crítico de los Acuerdos, hasta la modificación de leyes que garantizaban la participación de víctimas en el Congreso bajo una circunscripción especial (Echavarría et al., 2019).

Asimismo, centenares de líderes sociales y activistas han sido asesinados en los últimos dos años, y las investigaciones parecen no arrojar informaciones veraces y completas sobre la autoría y responsabilidad de los crímenes (Defensoría del Pueblo, 2019). El efecto sobre los líderes comunitarios ha sido devastador, tanto para quienes han sido perjudicados de manera directa por la violencia, como para quienes ven en su profesión y vocación una amenaza a su propia vida (Fundación Pares, 2018).

No obstante, hay una serie de momentos clave y procesos que representan un contrapeso a las dinámicas destructivas con propuestas de reconciliación

1 Este trabajo se enmarca dentro de la línea de investigación sobre "Educación para la Paz en Sociedades en Transición", desarrollada en el Centro de Investigación para la Paz y los Conflictos de la Universidad de Innsbruck (Austria), del cual la autora es co-directora. El trabajo de campo fue posible gracias al apoyo de la Universidad de Innsbruck (Austria), al Grupo de Investigación sobre América Latina de la Universidad de Viena (Austria) y al Centro de Estudios para la Reconciliación de la Universidad de Jena (Alemania). La edición final del texto se desarrolló durante una estadía de investigación en el Instituto Kroc en Universidad de Notre Dame. Mis agradecimientos sinceros a todas estas instituciones que apoyan la investigación para la paz.

2 Inclusive antes de su puesta en marcha, el Acuerdo ya contaba con un sinnúmero de movimientos en su contra que se concretaron en el "Plebiscito por la Paz", celebrado el 2 de octubre del mismo año, cuando triunfó el "No" expresado por una mayoría de la población que votó por rechazar los Acuerdos. A pesar de las modificaciones realizadas siguiendo a los voceros del "No", la polarización y descontento no ha cesado (Gómez-Suárez, 2017). 
y construcción de paz. De forma significativa, el sistema integral de verdad, justicia, reparación y no repetición (SIVJRNR) ha comenzado a implementarse con la Comisión para el Esclarecimiento de la Verdad (CEV), la Jurisdicción Especial para la Paz (JEP) y la Unidad Especial para la Búsqueda de Personas Dadas por Desaparecidas (UBPD).

La combinación de estas diferentes formas de justicia, verdad y reconciliación da un importante aliento a la construcción de paz territorial. Esta paz, de la que se habla en los Acuerdos, no es una sola, sino muchas paces, ancladas a los territorios donde nacen, a las personas involucradas en los procesos con sus características de géneros, lenguas, etnias y demás rasgos de los habitantes de la biodiversa geografía colombiana (Cairo et al., 2018). Hablamos entonces de paces senti-pensantes (Escobar, 2014), paces que se comprenden racionalmente pero que se viven y sienten emocional y corporalmente, que buscan re-crear el territorio como espacio de vida "apropiado material y simbólicamente [para que], vuelva a cumplir -o cumpla por fin- las funciones colectivas que ha perdido por el conflicto armado" (Peña, 2019).

En este cruce entre obstáculos y oportunidades para la construcción de muchas paces se han venido desarrollando expresiones artísticas que capturan con lenguajes metafóricos las memorias de la guerra y los anhelos de paz y reconciliación de muchos colombianos en el país y en el exterior. Reporteros gráficos reconocidos y profesionales, como Jesús Abad Colorado, documentalistas jóvenes, como Daniela Abad Lombana, y nuevas comunidades artísticas de personas reincorporadas, como Más Arte, Más Paz, gozan de gran aceptación y ganan en su capacidad de movilización y convocatoria.

También ellas ponen de manifiesto formas elicitivas de transformación de conflictos que dan vida a las paces territoriales, que llamamos formas "elicitivas" (Lederach, 1995; Dietrich, 2013; Martínez Guzmán, 2005) en tanto estos métodos artísticos evocan estrategias de transformación de las relaciones conflictivas entre antiguos adversarios, a partir de sus conocimientos locales y con un claro anclaje cultural. Desde un ángulo elicitivo, puede comprenderse que el Acuerdo Final ha dado un marco institucional para la reconciliación, pero son las comunidades afectadas las que marcan la dirección, los métodos y el ritmo mismo de sus cambios en los niveles personales, relacionales, culturales e institucionales (Paffenholz, 2015; Hancock y Mitchell, 2007).

El presente artículo es una contribución original hacia la comprensión de las maneras en que la reconciliación puede asentarse, "echar raíces" y florecer en contextos de post-acuerdo. Distanciándose de fórmulas prescriptivas 
que puedan transferirse como un método de fácil réplica de un contexto a otro, este trabajo traza derroteros elicitivos con dos objetivos principales. El primero es mostrar cómo la Investigación para la Paz (IPP) entrevé la importancia central de prácticas estéticas y éticas de reconciliación. Para ello, el texto condensa ideas fundamentales de la IPP sobre reconciliación y luego visibiliza tres prácticas artísticas que se están llevando a cabo en los territorios y que no están siendo documentadas en los anales oficiales de la historia de justicia transicional.

Un segundo objetivo es contribuir a la literatura especializada de la IPP sobre "pedagogías" para la reconciliación. Haciendo eco de las pedagogías para la paz (Gómez-Suárez, 2017; Paris-Albert, 2017), las pedagogías para la reconciliación incluyen el trabajo sobre actitudes y valores para fortalecer las capacidades para la convivencia pacífica (CEV, 2019b). Adicionalmente estas pedagogías responden a estrategias formales e informales en las cuales las artes se utilizan en función de la educación para la paz y para dar información a la ciudadanía sobre las estructuras institucionales del post-acuerdo. Sin embargo, no se trata únicamente de transmitir contenidos (por ejemplo, sobre las disposiciones legales o constitucionales del Acuerdo Final), sino que las pedagogías involucran a las personas de manera holística y afectiva. Las pedagogías para la reconciliación implican empatía, es decir, ampliar y mejorar la capacidad de ponerse en los zapatos de otros y otras, autorreflexionar sobre el papel que de forma pasiva o activa se ha adoptado en la guerra y en la construcción de paz. Cabe destacar de manera importante que las pedagogías son también métodos para empoderarse y adueñarse de la reconciliación.

En las páginas que siguen, se destilan las claves de las nuevas apuestas por la reconciliación a partir de dos preguntas fundamentales que obedecen a la curiosidad y al compromiso de la IPP para que sea relevante, útil y basada en una ética que abraza al mundo, a la naturaleza y a los seres humanos en toda su complejidad.

La primera pregunta es: ¿Cómo pueden los procesos de reconciliación nutrir las teorías de la IPP para no olvidar el llamado a hacer una investigación "al servicio de la humanidad"? (Martínez Guzmán, 2001) Así también se engloba uno de los propósitos que guían este trabajo y es rendir homenaje a Vicent Martínez Guzmán, pues gracias a sus ideas relativas a la pluralidad de la Filosofía para Hacer las Paces (Martínez Guzmán, 2001) y las capacidades humanas para realizarlas (Martínez Guzmán, 2005), en la IPP se hace posible identificar, reconocer y valorar las expresiones artísticas en las prácticas de reconciliación como insumo central de la investigación y el trabajo para construir muchas paces. 
La segunda cuestión es: ¿Qué tipo de reconciliaciones están siendo forjadas en Colombia a partir de las artes? Esta línea de investigación es aún incipiente y este texto pretende comenzar a recoger los desarrollos que sobre el terreno las comunidades y personas afectadas por el conflicto están efectivamente utilizando para reconciliarse.

El primer apartado del artículo se referirá a la importancia y características de los procesos de reconciliación desde los estudios de la IPP. Inspirados en la Filosofía para Hacer las Paces (Martínez Guzmán, 2001), la reconciliación anclada en las realidades de personas involucradas en los conflictos se mueve hacia el centro de la atención investigativa. En el segundo apartado se presenta brevemente el complejo escenario de post-acuerdo en Colombia y cómo la reconciliación se ha plasmado en la arquitectura institucional de los Acuerdos de Paz, en específico en el SIVJRNR. En una tercera sección se discuten ejemplos particulares de expresiones artísticas y las voces de las personas participantes e involucradas por medio de la observación y autoetnografía, entrevista semiestructurada y grupo de enfoque, como resultado del trabajo de campo llevado a cabo en Colombia en febrero y marzo de 2019. Finalmente, el artículo plantea claves para una pedagogía para la reconciliación, es decir, procesos educativos, artísticos y con alto contenido social que nos acerquen cada vez más a las muchas posibilidades y realidades que tenemos de "hacer las paces".

\section{Podemos hacer las reconciliaciones}

Con el título Podemos Hacer las Paces, Vicent Martínez Guzmán (2005) logró condensar uno de los mensajes más relevantes para la IPP, especialmente en situaciones de post-acuerdo: "los seres humanos, si queremos, podemos hacer las paces, podemos organizar nuestra convivencia de manera pacífica" (Martínez Guzmán, 2005: 15). Por la calidad de sus tesis y la relevancia para el caso colombiano, en este primer apartado se retomarán algunas ideas básicas de la Filosofía para Hacer las Paces (Martínez Guzmán, 2001; 2005), que indican elementos claves de la reconciliación en Colombia desde las prácticas artísticas y permiten comenzar a componer un derrotero de la pedagogía para la reconciliación.

Vicent Martínez Guzmán (1949-2018) fue un investigador para la paz valenciano, quien se entendía sobre todo como funcionario al servicio de la humanidad (Forastelli, 2015: 25) y abogaba por pedirnos cuentas mutuamente de cómo configuramos o "performamos" nuestras relaciones. Su argumento principal se basaba en que podemos "tomar conciencia de nuestra 
fragilidad y abrirnos a la diferencia y a la diversidad que enriquezca la pluralidad de maneras de ser humanos" (Martínez Guzmán, 2005: 19).

Martínez Guzmán desarrolló de manera conceptual y pedagógica su insistencia en ver, apreciar y reconocer las capacidades para hacer las paces como detentor de la Cátedra Unesco de Filosofía para la Paz, que ocupó en la Universitat Jaume I de Castellón desde 1999 hasta su muerte en 2018. En sus escritos y trabajo como docente, investigador y mentor, insistía en que el re-conocimiento de las capacidades y competencias para hacer las paces debía partir desde un necesario "giro epistemológico", entendido como un "cambio en lo que decimos cuando decimos que sabemos que podemos hacer las paces" (Martínez Guzmán, 2005: 21).

Martínez Guzmán (2005: 29) reclamaba que este giro requería recuperar el sentido semántico de la filosofía, como esas "ganas y afición apasionada por saber sobre la naturaleza y otros seres humanos". Poco a poco llevaba a sus lectores en sus reflexiones para encontrar las líneas de conexión entre paces y reconciliaciones:

[...] para hacer las paces necesitamos educarnos en un tipo de amor a los demás como a nosotros mismos, como otras partes de nosotros y nosotras mismos; atentos al clamor de los que sufren como expresión de la misericordia; rompiendo la espiral de la violencia con el amor a los enemigos y no devolviendo mal con mal; siendo diligentes en nuestras relaciones y tratándonos con cuidado unos y unas a otros y otras (Martínez Guzmán, 2005: 32-33).

Para Martínez Guzmán, el relacionamiento a partir del amor, la humildad, la ternura, el cuidado y la generosidad requería una concepción holística del ser humano y de la paz y los conflictos (Comins, 2015). Por un lado, argumentaba que no había dicotomía entre sentimientos y razón, como no la hay tampoco entre "exposiciones sistemáticas racionales y relatos considerados míticos” (Martínez Guzmán, 2005: 33), puesto que el ser humano tiene la capacidad de aprehenderse a sí mismo y a los demás en sus propias paradojas, sin necesidad de resolverlas, con aceptación, cuidado y "curiosidad profunda, diligente, cuidadosa” (Martínez Guzmán, 2005: 33). ${ }^{3}$

En este contexto aparece la práctica del cuidar como un acto autopoiético, es decir, de transformación propia y de los demás, pues "la persona que cuida se transforma, resignifica, se rehace, a través del ejercicio del cuidar"

3 Para Wolfgang Dietrich (2012), amigo entrañable de Vicent Martínez Guzmán, las características no-racionales de los seres humanos y, por lo tanto, de sus conflictos, hacen indispensable pensar en que la transformación debe ser también trans-racional, es decir, involucrando la racionalidad, pero yendo más allá de ella, pues la paz también involucra elementos emocionales, espirituales y corporales. 
(Comins, 2015: 41). Cuidar entonces aparece asociado a valores esenciales para una cultura de paz, como son la empatía y la ternura, pero también a habilidades fundamentales para la construcción de una Cultura de Paz (Comins, 2015: 42).

Especialmente en los momentos que siguen a la violencia y a las atrocidades, Martínez Guzmán encontraba que hay una necesidad de re-interpretar episodios violentos más allá de las explicaciones de los "señores de la guerra", que ven en la violencia la re-confirmación de sus tesis sobre una más grande necesidad de seguridad. ${ }^{4}$ Por el contrario, invitaba el filósofo a que los y las investigadoras para la paz vieran los episodios de violencia como síntomas de la necesidad de aceptar la vulnerabilidad y la fragilidad humanas, propias y de los demás, como una necesidad imperiosa para construir no solo muchas, sino imperfectas paces.

Aquí recordamos también el sentido que Francisco Muñoz (2006: 409) le daba al término de "paz imperfecta", en tanto que las paces son inacabadas, procesuales y se encuentran sigilosamente en todos los espacios donde se regulan de manera pacífica los conflictos.

Estas diferencias entre violencia y conflicto son de alta importancia, pues su diferenciación permite comprender el potencial productivo de la transformación pacífica y también la necesidad de la reconciliación tras la violencia (Jiménez Robles, 2016) e inclusive durante el acontecer de los conflictos y las violencias mismas. Vicent Martínez Guzmán (2005) afirmaba que la violencia comienza por romper la solidaridad intrínseca y comunicativa de las relaciones humanas:

La violencia también es la desatención de quien escucha, la falta de cuidado frente al que habla, desoír lo que se dice, romper la relación establecida por el efecto ilocucionario de comprensión. [...] La violencia comienza con la falta de reconocimiento de unos y unas a otras y otros como seres competentes para comunicarnos. La solidaridad no se crea sino que se reconstruye cuando reconstruimos lo que nos podemos pedir unos y unas a otros y otras, cuando reconstruimos la normatividad de cómo podríamos hacernos las cosas (Martínez Guzmán, 2005: 73).

Por ello, la reconciliación no es una "fase" tras el fin de la guerra, sino que puede ser entendida inclusive como un método de transformación durante los conflictos violentos que están aún sucediendo. Esta mirada procesual de la

4 Para Vicent Martínez Guzmán (2005: 55), el clamor por la "seguridad" debía estudiarse en sus raíces etimológicas para comprender la trampa que engloba. Seguridad significa sine-cura, es decir, sin preocupación, sin cuidado, con miedo a fallar, a ser frágiles y humanos. Por ello, según el autor, hay que destruir el mito de la seguridad y abrazar la inseguridad de las muchas paces. En el caso colombiano, esta gramática de la violencia y la in/seguridad puede ser estudiada en Echavarría (2010). 
reconciliación, anotan Leiner y Flämig (2012: 16), ha logrado condensarla de manera poética el alemán Friedrich Hölderlin (1770-1843), quien escribía al final de su novela Hyperion, que la reconciliación se desarrolla en medio de las disputas para que todo aquello que se ha separado vuelva a conciliarse. ${ }^{5}$ Es decir, el cese al fuego, la firma de acuerdos o tratados son excelentes momentos para iniciar procesos de reconciliación, pero la reconciliación es un hacer performativo que no requiere precondiciones, pues puede hacerle frente a la violencia, retarla y efectivamente servir como método para su transformación.

Los acuerdos de paz proveen plataformas importantes, pero no son equivalentes automáticamente a la re-construcción de la paz. Cuando se declara el cese al fuego, superar la concepción de las partes en conflicto como adversarios y crear instituciones que sostengan cambios culturales y estructurales profundos hacen parte de la transformación de los conflictos, que no se terminan con el fin de una guerra, pues son parte del trasegar humano.

Martínez Guzmán (2005: 125) propone que el conflicto "transforma también las percepciones de mí mismo, de los otros y de los temas en cuestión”. Así se hace bastante difícil comprender las intenciones de otros y se pierde la capacidad para articular las propias intenciones. En situaciones de conflictos de larga duración, como el colombiano, las imágenes de los enemigos llegan inclusive a institucionalizarse (Martínez Guzmán, 2005: 125-126).

Finalmente, la IPP postula que la transformación de conflictos debe también proponer alternativas y no solo describir la dialéctica (Martínez Guzmán, 2005: 126; Martínez et al., 2009). Al respecto, los escritos de Lederach (1995) sobre modelos elicitivos de transformación son bastante iluminadores. La transformación elicitiva de conflictos hace alusión a la capacidad de "evocar" que las partes en conflicto tienen para recuperar la comunicación y poder enfrentar las causas que alimentan dinámicas destructivas, y avanzar en procesos de transformación que les ayuden a hacer sus relaciones más funcionales.

Esta visión elicitiva de la transformación ha dado pie a que otros investigadores de paz, como Wolfgang Dietrich (2012, 2013 y 2017), creen métodos e instrumentos específicos para facilitadores y trabajadores de paces. Todo un engranaje filosófico, metodológico y práctico ha sido creado por Dietrich con el ánimo de apoyar a las partes en conflicto a orientarse en sus propias realidades conflictivas y reconocer nuevos cursos de acción que les permitan superar la violencia y transformar los patrones destructivos en el epicentro de los conflictos.

5 "Versöhnung ist mitten im Streit und alles Getrennte findet sich wieder" (Hölderlin, original en alemán, citado en Leiner y Flämig, 2012: 16). 
En este sentido, las relaciones humanas, que conectan a unos y unas con otros y otras aparecen lentamente en el centro de la atención de la IPP y la transformación elicitiva de conflictos. Si durante periodos prolongados de violencia y manejo destructivo de los conflictos las relaciones humanas se han marchitado, se han quebrado y las personas aparecen separadas, la reconciliación les invita a recordar que comparten conexiones humanas con todos y todas, inclusive con sus antiguos enemigos y adversarios. Desde el ángulo filosófico y antropológico de la IPP, se habla de "recordar", pues se parte de la base, como anotan Martínez Guzmán (2001 y 2005) y Francisco Muñoz (2006), que a los seres humanos los une una solidaridad intrínseca, inherente a su humanidad, que se resquebraja con la violencia.

Así se va pintando el lienzo de la pedagogía de la reconciliación con el relacionamiento en el centro de atención. Haciendo eco de la Imaginación Moral de John Paul Lederach (2016: 247-250), se recurre al lenguaje metafórico, porque la reconciliación exige un acto creativo, ya que se aboca a cambiar, a innovar, a des-acomodar las relaciones violentas y buscar nuevos ángulos de aproximación a los y las otras y nuevas formas de comunicación olvidadas o des-aprendidas durante épocas violentas.

La estética ayuda a quienes intentan pasar de ciclos de violencia a nuevas relaciones, y a aquellos de nosotros que deseamos respaldar esos movimientos para vernos realmente como quienes somos, artistas que alumbramos y mantenemos vivo algo que no ha existido hasta ese momento. [...] Hay que prestar atención a la imagen. Escuchar atentamente lo central. Confiar en la intuición y seguirla. Observar las metáforas. Evitar la confusión y el exceso de actividad (Lederach, 2016: 150-151).

Unos cuantos años más tarde y en compañía de su hija Angela Lederach, ahonda John Paul Lederach (Lederach y Lederach, 2014) sobre la importancia de las artes, no solo para expresar "lo indecible", sino también para capturar -aunque sea imperfectamente- las grandes capacidades que tienen las personas para recomponerse, curar y sanar. Para los autores, las artes hacen parte de los procesos de reconciliación a partir de dos cualidades fundamentales: espacio y movimiento. $\mathrm{Al}$ respecto, explican que, aunque sobre el concepto de reconciliación hay una amplísima gama de definiciones, ${ }^{6}$ muchos estudios comparten dos puntos de consenso. El primero es:

6 Existe una serie bastante amplia de dimensiones de la reconciliación (Rettberg y Ugarriza, 2016; Lederach y Lederach, 2014) que en la línea de IPP aquí expuesta pueden identificarse como una riqueza intelectual, afectiva, corporal y espiritual de las mismas relaciones interdependientes que se buscan re-conectar (Martínez Guzmán, 2005), inclusive en medio de las disputas (Leiner y Flämig, 2012) que relaciona a los seres humanos de forma intencional por primera vez con ciertos individuos y grupos (Du Toit, 2018). 
la idea de que la reconciliación surge de y se solidifica en torno a un foco de relaciones [...] guiada por una metáfora espacial del encuentro, una interpretación que propone lugares donde las personas enemistadas se reúnan, intercambien, se comprometan e incluso se abracen; donde creen y recreen terreno común en las historias contradictorias incrustadas en sus geografías sociales y físicas.

Otro punto de consenso es la ampliamente asumida noción de que como mejor se comprende la reconciliación es como proceso que implica alguna forma de movimiento [...] (Lederach y Lederach, 2014: 30).

Los movimientos a los que se refieren los autores recuerdan dos ritmos importantes que se observan en las prácticas de reconciliación luego de conflictos prolongados y violentos: los movimientos circulares, donde el cambio requiere repetición, un contenedor de resonancia y largo aliento, y movimientos que parecen penetrar la intensidad de las relaciones que sanan, desafiando marcos lógicos lineales e invitando a comprender las metáforas del cambio social que "aclaran las experiencias vividas [de las comunidades locales] y la intervención” (Lederach y Lederach, 2014: 238).

Por lo general, estas cualidades no se hallan en documentos y textos legales ni en descripciones de proyectos institucionales, sino en la puesta en marcha de intervenciones artísticas, como en música, cantos y cuencos, así como en la escritura de poesía. Aunque muchas de estas expresiones artísticas son auditivas y a veces invisibles, son intensamente palpables y sentidas por las comunidades participantes. De allí la importancia de que la IPP gane consciencia de que "los contenedores, la circularidad, las ceremonias, los rituales, procesos artísticos, la música y la poesía - por citar algunos elementos- proporcionan un componente central y no periférico del proceso de cambio" (Lederach y Lederach, 2014: 239).

Para contribuir a elicitar ese cambio, la IPP se vale de las ciencias de la educación y, en este caso particular, de la educación para hacer muchas paces y muchas reconciliaciones en contextos de post-acuerdo. En este sentido, es indispensable ir más allá de una educación moderna o una pedagogía bancaria en el sentido de Freire (citado en Paris-Albert, 2017: 67) y aventurarse hacia pedagogías liberadoras y creativas (Paris-Albert, 2017). Las pedagogías liberadoras promueven la reflexión sobre temas como "la no violencia, la igualdad de género, la responsabilidad ciudadana, la regulación positiva de los conflictos" (Paris-Albert, 2017: 73), re-integran las artes como parte fundamental de la educación ciudadana (Enslin y Ramírez-Hurtado, 2013) y enseñan sobre las dificultades y satisfacciones que nos brindan los procesos de paz y la reconciliación (Hernández, 2018). 
Por la integralidad misma de las experiencias de paces, las pedagogías creativas también incorporan didácticas y contenidos afectivos. Aprender a través del corazón, de manera empática y afectiva, parte de la premisa de que la condición humana básica es la conexión (Koppensteiner, 2018: 69). Aunque las pedagogías para la reconciliación pueden incluirse como parte de un currículo relacional y radicalmente empático (Murphy, 2018), la educación para la paz también ha contribuido de forma significativa al aprendizaje en espacios informales. Al tratarse de temas como transformación, las pedagogías para la reconciliación requieren vincularse a una amplia gama de espacios cotidianos y ampliar la matriz de prácticas estéticas y éticas que proveen oportunidades a todos y a todas para (aprender a) reconciliarse (Cremin y Archer, 2018).

Las reflexiones filosóficas y pedagogías inspiradas en los escritos de Martínez Guzmán y otros investigadores para la paz mencionados, aparecen hoy más actuales y relevantes que nunca cuando se intenta comprender cómo comunidades afectadas por el conflicto armado colombiano buscan re-conciliarse a través de prácticas artísticas después de la firma del Acuerdo Final.

\section{La reconciliación en la arquitectura del Acuerdo Final}

Tratar de comprender las apuestas de la reconciliación desde el texto del Acuerdo Final requiere comenzar con una aclaración elemental: el texto se produce en un con-texto, tiene pre-textos y está imbuido en relaciones intertextuales. Por motivos de espacio, no es posible explicar profundamente cada una de estas aristas, pero sí vale la pena mencionar los aspectos más importantes de ellas para descifrar cómo está pensada la reconciliación en la arquitectura del texto mismo.

En relación con el con-texto, es decir, con los discursos que rodearon la producción del texto del Acuerdo Final, uno de los temas más significativos fue el ambiente político de post-verdad que polarizaba a la sociedad colombiana. El contexto de post-verdad se caracterizó por el uso de medios (sociales) de comunicación como estrategia para engañar al electorado al circular historias políticas simplistas y altamente emocionales, que hicieron bastante difícil diferenciar entre información correcta e incorrecta, veraz y falsa, deshonesta y honesta en relación con las negociaciones, el Plebiscito por la paz en octubre de 2016 y luego el texto mismo del Acuerdo. La política de la post-verdad infló a la ciudadanía de miedo y odio y, de manera irónica, utilizó esta estrategia política para banalizar la política misma (Gómez-Suárez, 2017: 463). 
Relativo a los pre-textos del Acuerdo Final, es decir, a los discursos antecedentes que permitieron la creación del texto, encontramos el péndulo entre muchas guerras y muchas paces de la historia de Colombia (Echavarría, 2010). Las anteriores negociaciones con grupos guerrilleros, en especial los fallidos diálogos de El Caguán (1999-2002) con la misma guerrilla FARC-EP bajo la presidencia de Andrés Pastrana, fueron de gran relevancia para, por un lado, ayudar al equipo negociador a pactar unas reglas claras de comunicación y de mantenimiento de la agenda desde el comienzo (Arias, 2016). Por el otro lado, los anteriores diálogos fallidos resquebrajaron la confianza de la ciudadanía en la seriedad de la guerrilla bajo la sospecha de que los diálogos en La Habana fueran utilizados para re-amarse y tomar nuevos alientos para continuar la guerra (Gómez-Suárez, 2017; Hernández, 2019).

Un segundo pre-texto crucial fueron las negociaciones, desmovilizaciones y procesos de paz de gobiernos colombianos anteriores -especialmente en la década de 1990 - y los movimientos por la paz del país. De allí que las negociaciones y los Acuerdos de Paz se asentaban en experiencias ya llevadas a cabo de desmovilización, desarme y reintegración (DDR) de movimientos armados como la guerrilla del M-19 a comienzos de los años noventa y varios grupos paramilitares en el periodo 2003-2006. ${ }^{7}$ Asimismo, los recursos de construcción de paz en los territorios obedecían al trabajo de varias décadas de un sinnúmero de organizaciones y líderes sociales y de derechos humanos que habían tenido experiencias exitosas como las zonas de paz y comunidades de paz en Colombia y con vínculos transnacionales (Hancock y Mitchell, 2007; Mouly y Hernández, 2019). La experiencia de la Comisión Nacional de Reparación y Reconciliación (CNRR), creada a partir de la Ley de Justicia y Paz (Ley 975, de 2005), fue clave para pensar la arquitectura de la reconciliación como política pública en Colombia (Bueno, 2017).

Del Grupo de Memoria Histórica de la CNRR, en el año 2010 nace el Centro de Memoria Histórica (CMH) bajo la dirección de Gonzalo Sánchez. Los reportes, investigaciones y metodologías desarrolladas por el CMH constituyeron un aporte fundamental para proveer información relevante e investigaciones con un alto contenido audiovisual y pedagógico, que sirvieron para elevar la concientización acerca de los alcances de la guerra en Colombia, así como de los movimientos de resistencia pacífica

7 Según cifras de la Agencia para la Reincorporación y la Normalización (ARN), más de 73,000 personas (aproximadamente 65,000 hombres y 8,000 mujeres) salieron de grupos armados al margen de la ley entre los años 2001 y 2018: Ex-AUC aprox. 35,000; Ex-FARC-EP desmovilizados individualmente aprox. 19,000; Ex-ELN aprox. 4,000; Ex FARC-EP luego del Acuerdo Final de 2016 aprox. 13,000 (ARN, 2019). 
que históricamente les han hecho contrapeso (CNMH, 2013). Las pedagogías para la reconciliación actuales se nutren también de estos avances importantes en la escritura de una historia de paz imperfecta (Muñoz, 2006).

Una última arista son las relaciones inter-textuales, es decir, las interdependencias del Acuerdo Final con otros acuerdos de paz y arreglos institucionales fraguados en otros lugares del mundo. ${ }^{8}$ Reflexiones sobre los aspectos positivos y negativos de otros acuerdos y las lecciones sobre su implementación fueron consideradas por las partes directamente en el diseño y puesta en marcha de las conversaciones de paz. ${ }^{9}$ Vale la pena resaltar, por ejemplo, el papel que jugaron los países facilitadores, garantes y de apoyo al proceso de paz para superar las diversas crisis y que alimentaron aspectos decisivos de los acuerdos en su contenido, como la consideración de las experiencias de identidades sexuales diversas ${ }^{10}$ y la posición central de las víctimas y la sociedad civil en el texto del Acuerdo Final.

El con-texto, los pre-textos y las relaciones inter-textuales, aunque escuetamente mencionadas en los párrafos anteriores, dan muestra de los límites y el campo en que el texto mismo del Acuerdo Final se desarrolló.

En la composición del texto del Acuerdo un sinnúmero de personas e instituciones estuvieron presentes: el equipo negociador de las guerrillas FARC-EP, el equipo negociador del gobierno colombiano, delegaciones de los países garantes, cooperación internacional y asesores externos (Hernández, 2019; Bouvier, 2016). Estas diferentes voces y representaciones parecían comprender las diferentes fases y los retos propios de negociar y redactar el Acuerdo, para luego ponerlo a consideración de la ciudadanía colombiana por medio del plebiscito para empezar a implementarlo. Al final de la etapa de negociación en La Habana, en febrero de 2016, Sergio Jaramillo, líder del equipo negociador del gobierno, describía cómo las propuestas de la IPP habían sido parte de la idea central del proceso de paz colombiano.

8 Irlanda del Norte, El Salvador, Angola, Sudáfrica, así como Chad, Indonesia, Mali y Sudán fueron considerados y ponderados de manera explícita por los negociadores en tanto sus lecciones para el caso colombiano (Arias, 2016).

9 Las ideas de incluir una comisión de la verdad y la reconciliación, por ejemplo, en parte nacen por el estudio sistemático de países en transición alrededor del mundo. El monitoreo de la implementación del acuerdo por una Comisión de Verificación con el apoyo del instituto Kroc de Estudios Internacionales de Paz de la Universidad de Notre Dame provee además una mirada comparativa con más de 35 tratados de paz alrededor del mundo.

10 El gender mainstreaming del acuerdo, es decir, la transversalización de la mirada "generada" en el Acuerdo fue uno de los grandes logros de la experiencia colombiana y, desafortunadamente, también fue uno de los puntos que más votos y apoyo popular le restó a los mismos (Gómez-Suárez, 2017; Daşlı et al., 2018; Bouvier, 2016). 
Para Jaramillo (2016: 14), el proceso de paz no se entendía "sólo como el tránsito de las Farc a la vida civil, sino como la eliminación gradual de los factores que por tanto tiempo alimentaron la guerra." De allí que, según Jaramillo, la agenda de negociación preveía que luego de la firma del Acuerdo sería fundamental crear "plataformas de relacionamientos que produzcan cambios"' (Jaramillo, 2016: 14).

La fase de post-acuerdo se encaminaría a recortar las distancias que se han producido entre las comunidades en los territorios durante la guerra, deconstruir la desconfianza y hacer que "cada persona [se convierta en] un actor y no en un espectador de la construcción de paz" (Jaramillo, 2016: 15). Desde la perspectiva de Jaramillo (2016: 16), para re-crear el círculo virtuoso de la paz se hace necesario que las instituciones respondan con cambios para la paz, que el Estado eche raíz en el territorio ${ }^{11}$ y que la gente participe y se movilice en espacios de diálogo para que pueda fluir la energía de la paz territorial.

Haciendo eco de esta estructura tripartita, la arquitectura institucional para la reconciliación sería uno de los puntos de apoyo necesarios (aunque no suficientes) para elicitar muchas reconciliaciones. En el Acuerdo Final se prevé la arquitectura de la reconciliación con mayores énfasis en los siguientes apartados:

2.2.4. Garantías para la reconciliación, la convivencia, la tolerancia y la no estigmatización, especialmente por razón de la acción política y social en el marco de la civilidad. Esto mediante la Conformación del Consejo Nacional para la Reconciliación y Convivencia.

3.4.7.4.4. Ejecución del Programa de Reconciliación, Convivencia y Prevención de la estigmatización con la participación de las entidades territoriales.

5.1. Sistema Integral de Verdad, Justicia, Reparación y No Repetición [SIVJRR]. Reconocimiento de las víctimas, el reconocimiento y establecimiento de responsabilidades, y en general el reconocimiento por parte de toda la sociedad de la necesidad de aprovechar esta oportunidad para construir un mejor futuro sobre la base de la justicia social, el respeto y la tolerancia (ARN, 2019).

11 Es importante retomar las consideraciones del investigador Luis Peña (2019), quien anota que la procedencia urbana y elitista de los negociadores del gobierno ha marcado su perspectiva de que la paz y la reconciliación territorial requieren "llenar el territorio" de instituciones, lo cual entra en contradicción con la idea de paz territorial sentí-pensante discutida al comienzo (Escobar, 2014). Debe haber un equilibrio entre la presencia del Estado y la re-creación del territorio empoderado por la paz, lo cual implica que la paz en el post-acuerdo debe ser llevada a cabo por las comunidades afectadas en la recreación espacial (Peña, 2019) e imaginativa (Lederach, 2016) de sus propias paces, donde las artes y la participación ciudadana - no las instituciones del Estado- sean los protagonistas. 
En esta dirección, vale la pena resaltar que en el Acuerdo Final el SIJVRR $^{12}$ se constituye en el eje de la justicia transicional como el pilar de la verdad, la reconstrucción de la memoria histórica y la justicia "en perspectiva de reconciliación” (Bueno, 2017: 18, énfasis añadido). Es decir, el SIVJRR no solo apunta a responder a las verdades históricas, judiciales, éticas y humanitarias, sino también a reconstruir los relatos desde las comunidades afectadas y generar una consciencia pública de los horrores de la guerra (Bueno, 2017: 19).

Estas cualidades se hacen palpables al indagar por la composición, objetivos y características del SIVJRR en clave de reconciliación. El SIVJRR está compuesto por mecanismos judiciales y extrajudiciales con tres órganos fundamentales: 1) la Comisión para el Esclarecimiento de la Verdad, la Convivencia y la No Repetición (CEV) como mecanismo imparcial, independiente, transitorio y extrajudicial; 2) la Unidad Especial para la Búsqueda de Personas Dadas por Desaparecidas (UBPD), con carácter humanitario y extrajudicial; y 3) la Jurisdicción Especial para la Paz (JEP) con funciones judiciales para investigar, juzgar y sancionar delitos cometidos en el contexto y en razón del conflicto armado (Goebertus, 2016). ${ }^{13}$

Los objetivos también difieren y se complementan entre sí: la CEV busca:

Escuchar a víctimas, responsables y testigos del conflicto armado de todos los sectores, regiones y condiciones sociales en el país para lograr un relato amplio y comprensivo de los hechos y contextos que explican medio siglo de guerra (CEV, 2019a).

La UBPD:

tiene como objetivo dirigir, coordinar y contribuir a la implementación de las acciones humanitarias de búsqueda y localización de personas dadas por desaparecidas en el contexto y en razón del conflicto armado que se encuentren con vida y, en los casos de fallecimiento, cuando sea posible, la recuperación, identificación y entrega digna de cuerpos (UBPD, 2019a).

Por último, la JEP:

tiene la función de administrar justicia transicional y conocer de los delitos cometidos en el marco del conflicto armado que se hubieran cometido antes del 1 de diciembre de 2016 [...] para satisfacer los derechos de las víctimas a la justicia, ofrecerles verdad y contribuir a su reparación (JEP, 2019).

12 La integralidad del sistema ha sido puesta en juego varias veces desde la aprobación del Acuerdo Final por el Congreso al término del año 2016. En gran medida, el con-texto de post-verdad que acompañó las negociaciones no ha cesado, sino que se ha recrudecido tras la elección del presidente Iván Duque en junio de 2018, y el Acuerdo Final ha sido desarrollado con grandes dificultades legislativas en el Congreso de la República (Echavarría et al., 2019). 13 Además de estos tres órganos, el SIVJRR también contempla medidas de reparación integral para la construcción de paz y las garantías de no repetición. 
Sus coordenadas temporales también hacen que el sistema sea integral, puesto que si bien la CEV tiene un mandato por tres años, la JEP y la UBPD operarán por un periodo de 20 años.

Vale la pena destacar que el SIVJRR está atravesado por una preocupación conceptual y metodológica por las pedagogías que se requieren para la reconciliación. ${ }^{14}$ Por motivos de espacio y alcance, este artículo se concentra en la $\mathrm{CEV}$, además porque su misión y especialmente la entrega del informe final en 2021 hacen que el trabajo de la IPP en su favor sea necesario y urgente.

En la metodología de la CEV (2019b: 23), la pedagogía se describe como el trabajo sobre actitudes y valores para fortalecer las capacidades para la convivencia pacífica. La CEV anota que su trabajo pedagógico se encamina a priorizar redes de niños y niñas, jóvenes, mujeres y personas mayores, y a las integrantes de las instituciones educativas.

A través del arte y las expresiones culturales, se activarán experiencias vitales que busquen tocar las emociones, generar confianza colectiva, compasión ante el dolor de las víctimas, responsabilidad entre generaciones, etnias, géneros, espiritualidades, sectores y perspectivas políticas, e indignación ante la destrucción de la naturaleza que permitan su reconocimiento mutuo y la posibilidad de caminar colectivamente y ser creativos en dinámicas y lógicas no-violentas de la sociedad (CEV, 2019b: 23).

Las artes y la cultura, adicionalmente, aparecen como una de las dimensiones que la CEV prioriza en relación con el cumplimiento de su mandato. Por ejemplo, se busca no solo "identificar los contextos culturales en los que se despliega el conflicto” (CEV, 2019b: 31), sino también convocar a la "producción, activación y visibilización de expresiones artísticas relacionadas con la misión y mandatos de la Comisión" (CEV, 2019b: 32), participar en eventos artísticos y culturales con contenidos propicios a la instalación de los objetivos y misión de la CEV, y hacer alianzas estratégicas para la "producción, divulgación, circulación y apropiación de la conciencia sobre los asuntos de la cultura que deben transformarse o potenciarse" (CEV, 2019b: 32).

Así, aparecen pedagogía y artes aunados desde el comienzo en el SIGVRR y, en este caso particular, en la CEV. Para la comisionada Lucía

14 Por ejemplo, la UBPD (2019b) promueve la “pedagogía para la búsqueda”, que quiere "facilitar la comprensión del mecanismo, las formas de acceso y la participación activa de víctimas, organizaciones y la sociedad en general, en los procesos de búsqueda humanitaria y extrajudicial [...] así como promover el reconocimiento y la solidaridad de la sociedad en la búsqueda de los desaparecidos en contexto y razón del conflicto armado en Colombia”. Estas pedagogías para la búsqueda se dirigen a comprender el sentido de la búsqueda misma, así como concertar círculos de saberes creativos, diálogos que generan sensibilidad y solidaridad. 
González (citada en CEV, 2019c), así como la guerra transformó y destruyó la cultura, debe también hacerse un esfuerzo institucional por visibilizar, reconocer y valorar

las expresiones estéticas en procesos restaurativos de las víctimas y cómo hay un cúmulo de aprendizajes sociales de las víctimas que crearon cantos, tejidos, murales, performances, bailes, obras de teatro y poemas para narrarse y expresar sus esperanzas. "El arte es un proceso restaurador. Es una expresión profunda de las culturas y una forma de reconstruir el ser social en su territorio" (CEV, 2019c).

La CEV ha animado, acompañado y visibilizado grandes expresiones artísticas, como la obra Fragmentos de Doris Salcedo (Museo Nacional de Colombia, 2019), un contra-monumento realizado por la artista con el hierro fundido de las armas entregadas por las FARC-EP.

Para que la experiencia de una víctima pueda ser comprendida en toda su gravedad, debe ser expresada, narrada y compartida. Por este motivo, Fragmentos es un lugar de memoria que tiene como misión producir y exhibir, durante un periodo equivalente a la duración del conflicto, diferentes obras de arte que reelaboren la memoria de la guerra. Cada año, un artista será invitado a que presente aquí su mirada e interpretación de nuestro pasado reciente. No tendremos solo un monumento, sino múltiples contramonumentos cambiantes, polifónicos y vivos. Fragmentos reclama una memoria permanente en estado de transformación (Salcedo, 2018).

Por ello, más allá de la reparación simbólica, las artes en el postacuerdo no solo aparecen como expresión de la violencia y de los deseos de reconciliación, sino que operan como mecanismos fundamentales para hacer valer los derechos de víctimas y articular las perspectivas de victimarios en las tramas de las violencias, las paces y las reconciliaciones en Colombia (Sierra, 2019). Así se comienzan a hilar las estéticas de las pedagogías para la reconciliación y las artes en relación con la justicia transicional en contextos de post-acuerdo, tan variadas como posiblemente pueden serlo las mismas miradas y experiencias de guerras y paces.

\section{Tejiendo voces, historias e imágenes de la reconciliación}

Como "reconocer, dialogar y humanizar" describe Gonzalo Sánchez (2019) el aporte pedagógico que múltiples expresiones artísticas comunican y evocan en torno a los procesos de reconciliación en Colombia. Haciendo eco de esta mirada, en esta sección se reportan los resultados de investigación cualitativa sobre prácticas artísticas para la reconciliación en Colombia. Esta muestra no intenta ser representativa, sino poner de manifiesto la diversidad de prácticas artísticas a lo largo y ancho del territorio en términos de 
geografías, formas de expresión, perspectivas de participantes y técnicas de investigación. Los tres ejemplos ilustrativos fueron seleccionados al compás de las visiones de paces territoriales, ancladas en sus contextos culturales y obedeciendo a los siguientes criterios:

1. Se ubican en tres regiones diferentes de Colombia (Bogotá, Medellín y Barrancabermeja), geografías cambiantes, composiciones étnicas diversas.

2. Presentan tres formatos artísticos diferentes (fotografía profesional, cine documental y artesanías).

3. Son prácticas artísticas realizadas por profesionales y no profesionales.

4. En ellas participan hombres y mujeres.

5. Fueron investigadas por la autora por medio de tres instrumentos diversos (autoetnografía, entrevista semiestructurada y grupo de enfoque).

6. Los instrumentos de investigación brindan una mirada tripartita: la perspectiva de quien visita o atiende la exposición de fotografía (quien "consume") y la perspectiva de las artistas creadoras de cine documental y de artesanías (quienes "producen").

A pesar de su heterogeneidad, estas prácticas artísticas tienen en común que han sabido comunicar, enternecer y articular "las vivencias de la guerra como una diversidad de dolores compartidos" (Sánchez, 2019) y las muchas posibilidades de reconciliación en una pluralidad de paces territoriales.

La primera sección hace alusión a un relato autoetnográfico de la exposición fotográfica El Testigo, de Jesús Abad Colorado, en el Claustro de San Agustín (Bogotá, febrero de 2019). La segunda nace a partir de la entrevista semiestructurada concedida por la documentalista Daniela Abad Lombana, sobre la relación entre artes y reconciliación, paces y violencias (Medellín, marzo de 2019). La tercera narrativa es producto de un grupo de enfoque realizado con la asociación Más Arte Más Paz de Magdalena Medio (Barrancabermeja, marzo de 2019). Más que un recuento de cada una de estas vivencias, el texto se concentra en la segunda pregunta de investigación guía anotada al comienzo de este artículo: ¿Qué tipo de reconciliaciones están siendo forjadas en Colombia a partir de las artes?

\section{Jesús Abad Colorado: El Testigo}

Probablemente el fotógrafo de guerra más famoso de Colombia, Jesús -alias "Chucho"- Abad Colorado, ha cubierto cómo el conflicto armado ha vulnerado comunidades en todo el territorio por varias décadas (1992-2018). Sus imágenes fueron condensadas en las páginas de periódicos como $\mathrm{El}$ Colombiano, siempre mostrando expresiones humanas de profundo dolor. 
Con su reporte gráfico, Chucho no solo muestra las vivencias del horror de la guerra, sino también cuán necesaria y sentida es la reconciliación.

Más de 500 fotografías componen la exposición El Testigo, cada una de ellas rodeada de descripciones con historias precisas de cuándo y dónde fueron tomadas las imágenes, así como de sus protagonistas (Universidad Nacional de Colombia, 2019). El Testigo se despliega en el Claustro de San Agustín, un lugar en medio de las decisiones de poder político central, por su proximidad a la casa de la presidencia -el Palacio de Nariño-, el Congreso de la República y el Ministerio de Hacienda. Además de las imágenes, la exposición está acompañada de gráficos y mapas que proveen cifras y contextualizaciones para los visitantes (Universidad Nacional de Colombia, 2019). Extractos de poesía de Maya Angelou, palabras de reflexión del artista y de la curadora María Belén Sáez de Ibarra están escritas en los muros de las paredes, entremezcladas con las fotografías.

Más de 70 mil personas visitaron la exposición desde su inauguración el 20 de octubre hasta finales de diciembre de 2018, de allí que se extendieron las fechas de la muestra hasta finales de abril de 2019 (Semana, 2019). Gracias a esta extensión, se realizó la visita en febrero de 2019, de la cual se comparten apartados autoetnográficos como una breve muestra cualitativa de la experiencia como visitante.

Llego a El Testigo un jueves en la mañana. El sol resplandece en la capital, como solo sucede a 2,600 metros de altura en el Trópico, con calidez, pero sin quemar.

Luego de una reunión en el primer piso del Claustro, en las oficinas del CAPAZ con Martín y Luis - mis compañeros de viaje en esta aventura académica- vamos por un momento al primer piso.

Habíamos previsto la visita, pero aún siento cómo mi piel se pone de gallina; ya sé lo que me espera: las fotografías de Chucho, que llevo guardadas en mi memoria como tatuajes.

Aquel niño cerrando los botones de la camisa de un hombre muerto sobre una camilla, con su camisa de rayas, el niño con una expresión de amor y solemnidad que solo pueden hacerme pensar que se trata de su padre. Su padre, quien posiblemente murió en un acto violento, injusto y cruel.

No recuerdo bien dónde fue tomada esta imagen, solo sé que cuando pienso en Jesús Abad Colorado, esta imagen llega a mi mente, acompañada de la piel de gallina.

Trato de componerme: "no es tu padre", me digo, tratando de consolarme, pero sé que es "alguien" tan importante como lo fue mi padre para mí, alguien por quien el niño que le abotonaba la camisa se enternecía y estremecía.

Comenzamos a caminar por la exposición y ahí está: veo la foto del niño. Tomada en San Carlos (Antioquia) luego del asesinato del padre por los paramilitares en 1988. 
Imágenes llenas de dolor.

Veo a un perro que parece dormir en un andén y sobre su lomo están marcadas las siglas de las AUC. ;Cuánto sufrimientos nos causamos a nosotros mismos y la naturaleza!

En medio de la exposición han colocado troncos de árboles, que salen del piso como la arquitectura de Hundertwasser: superficies no niveladas, que dan cuenta de la vida y su indomabilidad.

Las lágrimas dejan de correr tímidas por mis mejillas y se convierten en llanto.

Salgo al corredor -mi abuelo le llamaría cortijo, pues es un edificio colonial con un patio central al aire libre.

Cómo me duele todo el cuerpo (Echavarría, inédito).

\section{Daniela Abad Lombana: Historias de Dos Abuelos}

Carta a una Sombra (2015) y The Smiling Lombana (2018) son los documentales largometrajes que la joven directora de cine, Daniela Abad Lombana, ha escrito, producido y dirigido con grandes éxitos. Carta a una Sombra es la filmación del libro escrito por su padre, Héctor Abad Faciolince, El Olvido que Seremos (Abad, 2006), sobre su abuelo paterno Héctor Abad Gómez, médico defensor de Derechos Humanos asesinado en 1987. El segundo documental versa sobre su abuelo materno, Tito Lombana, un artista que buscó una mejor fortuna en Europa y trabajó satisfaciendo los gustos de narcotraficantes, para luego ser capturado y condenado a una cárcel en Estados Unidos.

La historia pública de Héctor Abad y su muerte, y la vergüenza y el silencio alrededor de Tito Lombana parecieran representar dos figuras antagónicas de la violencia y la paz, pero Daniela problematiza esta simple dualidad e invita a una reflexión que habla de hacer paces imperfectas y tejer muchas reconciliaciones a través del arte.

Al comienzo de marzo de 2019, Daniela llega a la Colegiatura Colombiana en Medellín para realizar una entrevista, cuyo tema principal aborda las relaciones entre arte, violencia y paz, en el sentido de cómo el arte puede legitimar ciertos tipos de violencias y también cómo puede despertar la mirada para alentar a la construcción de paz. La entrevista comienza con dos preguntas fundamentales: ¿Quién es Daniela? y ¿cómo las artes contribuyen a la reconciliación? Pero Daniela no responde directamente, sino que va más allá y propone algo diferente. 
Para mí, las mejores películas funcionan [...] en forma de eco, como que después de una semana se da cuenta que [uno] sigue pensando en lo que vio [...] lo que yo esperaría cuando yo hago películas es generar pensamiento en ese sentido [...] en que la gente se quede reflexionando sobre algo durante unos días [...]. Creo que eso se logra [...] a través de la emoción [...]. No creo que el arte [...] funcione primero por la razón y después por la emoción, sino que esos razonamientos primero pasan por la emoción y después pasan por la razón y al pensamiento (entrevista con Daniela Abad, en 2019).

Daniela intenta que en sus producciones el espectador se vincule con la historia que ella está contando, "se emocione, llore, se ría, esté atento, no pierda la atención” (Abad, 2019).

El arte deja tal vez más una sensación [...] el arte no se encarga -creo yo- de dejar datos, sino más bien una sensación, para que después si quieres vayas e investigues, pero no creo que los documentales deben ser... como Wikipedia [...] A través del documental, yo me voy a emocionar, y a través de la emoción, yo voy a tener cierta información. Pero el objetivo del documental no es informar, es emocionar (Abad, 2019).

Por ello, argumenta Abad (2019) que el arte no es algo "bueno" en sí mismo, sino que cineastas (o artistas en general) intentan que los espectadores se sensibilicen hacia ciertos sentimientos y pensamientos, pues el arte se encamina precisamente a llamar la atención sobre las huellas dejadas por la violencia. Además, las intervenciones artísticas en momentos y espacios de construcción de paz y reconciliación invitan al diálogo sobre procesos en los cuales la sociedad termina muy vinculada, como el narcotráfico (Abad, 2019). Bien sea a través de la creación de nuevos espacios territoriales para la memoria - por ejemplo, la Casa Museo de la Memoria (CMC) en Medellín (Echavarría, 2015)-, como alrededor de la sacralización del terror sin reconstrucción - por ejemplo, la estatua El Pájaro, de Fernando Botero, en la Plaza San Antonio en Medellín, que fue bombardeada por la guerrilla de las FARC-EP en 1995 y nunca fue restaurada-, "lo más importante es que haya una conversación" (Abad, 2019), un diálogo sobre las violencias sufridas y prolongadas (de forma intencional o por inacción) de unos y unas frente a otros y otras.

Al final de la entrevista, Daniela Abad anota algo que remite directamente a los sentimientos para las muchas paces y reconciliaciones (Martínez Guzmán, 2005: 140-142): "Para mí lo más bonito es haber logrado conmover a alguien" (Abad, 2019). Sin duda, sus documentales con-mueven profundamente, mostrando a los espectadores el amor por su familia y recordando la esperanza y la reconciliación que yace en la misma fragilidad humana. 


\section{Más Arte, Más Paz: Artesanias con Aires de Reconciliación}

El tercer ejemplo artístico de las muchas reconciliaciones que se tejen en Colombia se desarrolla en Barrancabermeja, en el Magdalena Medio, una de las regiones con mayores índices de violencia en la historia del conflicto armado en Colombia, con su punto álgido entre 1998 y 2002, periodo durante el cual se disputaron el territorio y sus habitantes las guerrillas y paramilitares (CNMH, 2013: 170). Pero el Magdalena Medio también ha sido una región caracterizada por el empoderamiento pacifista, siendo el Programa de Desarrollo y Paz del Magdalena Medio (PDPMM) una de las experiencias más exitosas en Colombia de organización comunitaria y resistencia no-violenta.

La belleza del territorio es exuberante, la temperatura y la humedad son altas. Bajo árboles de mango y tomando agua de coco, en marzo de 2019 la autora tuvo la oportunidad de facilitar un círculo de conversación con un grupo de enfoque con las mujeres pertenecientes a la asociación Más Arte, Más Paz. La asociación nació en 2018 con apoyo de la Agencia para la Reincorporación y la Normalización (ARN), ${ }^{15}$ y está compuesta por víctimas del conflicto armado y la comunidad afectada, así como también por mujeres excombatientes, quienes han dejado las armas de grupos ilegales y se encuentran en proceso de reintegración o reincorporación.

El grupo de enfoque tuvo la participación de 10 miembros de la asociación, a quienes se les pidió que contaran los antecedentes de su trabajo conjunto. Ellas relataron que Más Arte, Más Paz nació como iniciativa productiva hacia una vida independiente por parte de las excombatientes. Ellas se habían conocido con anterioridad durante seminarios y talleres dictados como parte del Modelo de Reintegración Comunitaria (MRC) que la ARN lleva a cabo con apoyo de la Organización Internacional para las Migraciones (OIM).

Durante estos encuentros, las excombatientes decidieron guardar su anonimato y no develar a cuál o cuáles grupos ilegales habían pertenecido y en qué regiones habían estado activas durante la guerra. Esta decisión se debía a que sabían que la composición mixta del grupo, reinsertadas y reincorporadas, implicaba que habían luchado como enemigas durante el conflicto armado. Querían llevar a cabo sus sesiones de acercamiento, reconciliación y perdón, así como de sanación de heridas personales, de manera comunitaria, con sus nuevas compañeras e inclusive amigas. Esto no implicaba esconder

15 En la actualidad, la ARN acompaña los procesos de reintegración de aproximadamente 6,000 excombatientes a la vida civil y la reincorporación de más de 13,000 excombatientes de las FARC-EP a raíz de la firma del Acuerdo Final (ARN, 2019). 
o silenciar el dolor, sino contarlo, pero de manera que los nombres propios se compartirían más adelante, pues -en su opinión- no eran fundamentales para su proceso.

Al cabo de varios meses, las mujeres se dieron cuenta de que en la mayoría de sus sesiones se sentaban a tejer, que unas les enseñaban a las otras a coser, que mover sus manos y tejer de forma colectiva las ocupaba. "Era como una meditación”, dijo una de ellas. Artesanías de Colombia les brindó apoyo técnico a través de su Laboratorio de Diseño e Innovación, y con el apoyo de artesanos de la región y haciendo uso del conocimiento que ya muchas de ellas tenían, quisieron entonces fundar su propia asociación de artesanías.

Pero antes de fundarla oficialmente, sintieron que debían desvelar sus verdaderas identidades. Así, las mujeres que escucharan a las demás supieran quiénes eran en la guerra y quiénes son hoy "en la civil” (como ellas dicen), podrían tomar la decisión consciente e informada de pertenecer a la asociación. El proceso de desvelamiento fue intenso y profundo, según cuentan. Fueron varias semanas de reuniones, de pedir y conceder perdón, de rituales y cantos, y algunas despedidas de quienes no se sintieron en condición de continuar. Las que permanecieron e inclusive otras desmovilizadas a raíz del proceso con las Autodefensas Unidas de Colombia (AUC) de 2006 fundaron Más Arte, Más Paz en diciembre de 2018.

Comenzando su labor se sienten optimistas, pues ya tienen productos que se venden con popularidad en varias ferias, como taburetes, canastos y mochilas, e inclusive han publicado un calendario con fotos de las artesanías. En el calendario puede leerse: "En Barrancabermeja, las artesanías tienen alma. Cada una de ellas lleva nuestra esencia, nuestros sueños y nuestra esperanza de construir un futuro mejor para todos" (Más Arte, Más Paz, 2019). También han adquirido un pequeño stand en el aeropuerto de Barrancabermeja. Allí tienen la posibilidad de vender sus productos y darse a conocer, contar esta historia de manos artesanas, perdones tejidos y reconstrucción de vidas. ¿Es esto reconciliación para ellas? ¿Se sienten reconciliadas? ¿Cómo les ha ayudado el arte en este proceso? Estas son algunas respuestas durante el grupo de enfoque:

Mi reconciliación no fue solo con las reinsertadas, sino con todo el grupo [...] llegamos a reconciliarnos a través del amor y sentí que un peso salió de mi vida [...] puedo mirar a otra persona de otra manera (Mujer 1).

La reconciliación comenzó conmigo misma [...] La guerrilla mató a toda mi familia e ingresé a las autodefensas pensando "voy a hacer justicia" [...] era como una máquina [...] el odio y el rencor salían a flote (...) [La reconciliación para mí fue] El amor de Dios que llega al corazón de uno y cambia la vida de otro modo [...] Aquí todos perdimos. 
Dios tiene perdón para todo. Yo también quiero que me perdonen (Mujer 2).

Entendimos que ellas tienen problemas y sufrimiento. Ellas estaban aisladas. Buscamos unirlas por medio del arte. [...] [Reconciliación para mí fue] reconciliarme con ellas (Mujer 3).

Para mí el arte es como la miel. La miel en un plato, que es atractiva, que me arrimo, hasta saciarme. Eso es el bordado, aguja y pepitas. [Mostrando el calendario, lee] "En Barrancabermeja las artesanías tienen alma." Alma con tranquilidad del espíritu (Mujer 4).

Soy una mujer también en proceso de reintegración y quiero pedirle perdón a la comunidad. Perdón a través de los tejidos. Uno teje y se mete en eso. [Con] Tejer se le llena el alma a uno de orgullo (Mujer 5).

El cambio empieza de adentro hacia fuera, no al revés. [Entona una canción y canta] "No hay nada perfecto, amor, el amor es imperfecto [...] lo perfecto es inhumano" (Mujer 6).

La relación con la Filosofía para Hacer las Paces se hace evidente: si los seres humanos somos imperfectos, no solo será nuestra paz también imperfecta e inacabada, también lo serán nuestras reconciliaciones.

\section{Conclusiones}

Este artículo empezó con una invitación a adentrarse en dos preguntas fundamentales: ¿Cómo pueden los procesos de reconciliación nutrir las teorías de la IPP para no olvidar el llamado a hacer una investigación "al servicio de la humanidad” (Martínez Guzmán, 2001)? y ¿qué tipo de reconciliaciones están siendo forjadas en Colombia a partir de las artes?

De la mano de las enseñanzas de Martínez Guzmán, se recorrió un camino amplio de ideas, experiencias y reflexiones que ofrecen generosamente otros investigadores e investigadoras para la paz. Ellos y ellas nos hablan de la importancia de recordar la pluralidad de seres humanos y abrazar la fragilidad no como una debilidad a superar, sino como la fuente misma de las paces relacionales. Enfrentar los conflictos y las violencias a partir de la vulnerabilidad implica también que con valentía se pueden tejer cambios políticos e institucionales, como fue el caso con el Acuerdo Final, y además cambios personales y relaciones, como muestran las experiencias artísticas investigadas.

Ver las imágenes de las personas y comunidades directamente afectadas, aprender de sus historias de vida a través del cine y escuchar sus voces al compartir un agua de coco son vivencias que se nutren de una tierra fértil que es la firma del Acuerdo Final, pero que se debe continuar cultivando -en el mejor 
sentido que Martínez Guzmán le daba al término-, para que estas muchas paces y reconciliaciones continúen teniendo aire para respirar y nutrientes para continuar creciendo. Sin pretender que sea un modelo prescriptivo y completo, sino como un derrotero elicitivo e imperfecto, se condensan aquí algunas ideas claves de las pedagogías para la reconciliación:

1. Si la violencia y los conflictos separan y crean vacíos de comunicación entre las partes, la pedagogía para la reconciliación apunta a acercarlas, a permitir escuchar los unos y unas a otros y otras.

2. Si la violencia y los conflictos han impedido articular las intenciones y no se reconoce a los antiguos adversarios, la pedagogía para la reconciliación invita a comunicar de manera congruente y noviolenta, para recuperar la capacidad de escuchar empáticamente y expresarse de forma auténtica.

3. Si la violencia y los conflictos enredan las relaciones y dificultan ver formas alternativas de relacionarse, la pedagogía para la reconciliación ayuda a reconocerse como potenciales facilitadores de problemas propios, a empoderarse y apreciar que los seres humanos tienen la capacidad para juntos identificar nuevos cursos de acción.

4. Estos re-encuentros, o llamados a recordar la humanidad común, no pueden limitarse a enganchar a las antiguas partes en conflicto a través de la razón ni de forma puramente analítica. Las estéticas de la transformación personal, colectiva e institucional requieren el cambio social metafórico, auditivo y cíclico, y por lo tanto pedagogías y didácticas afectivas que apunten a con-mover de manera integral.

5. Aunque el marco institucional de la reconciliación no hace alusión directamente a la pedagogía, en el desarrollo de las instituciones del SIVJRNR se hace explícita la necesidad de diseñar e implementar pedagogías de verdad y de reconciliación. Este es un nicho de gran relevancia para la educación para la paz y debe ser aprovechado a cabalidad para la construcción de una paz estable y duradera.

6. Las artes son un elemento central de las reconciliaciones, pues el lenguaje y el oficio metafórico de los y las artistas son -a su vez- el lenguaje y el oficio de los actores y actrices de construcción de muchas paces y reconciliaciones. Las artes permiten que los y las artistas se mantengan en contacto con su pulso o vida interior y, cuando las comparten, permiten participar a otros y otras de sus procesos internos y pertenecientes a las comunidades que no solo han sufrido, sino que también se curan colectivamente. Su sanación inspira y transforma también a la comunidad. 
El cambio que se observa, se escucha y se palpa en las prácticas artísticas mencionadas debe ser amplificado, como ondas. En Colombia se tiene una oportunidad invaluable para que el Acuerdo Final se traduzca en muchas reconciliaciones, pues, aunque sean imperfectas como el canto del amor, son como el aire que mantiene viva el alma. Desde el diario y artístico quehacer, todos y todas podemos hacer las paces.

\section{Referencias}

Abad, Daniela (2019), En entrevista con Josefina Echavarría, en Medellín, Colombia, 5 de marzo de 2019.

Abad, Héctor (2006), El Olvido que Seremos, Colombia: Planeta.

Acuerdo Final (2016), Acuerdo final para la terminación del conflicto y la construcción de una paz estable y duradera, Colombia: Oficina del Alto Comisionado para la Paz. Disponible en: http://www.altocomisionadoparalapaz.gov.co/procesos-yconversaciones/Documentos\%20compartidos/24-11-2016NuevoAcuerdoFinal.pdf [4 de julio de 2019].

Arias, Gerson (2016), "Contexto Histórico: Lecciones Aprendidas para la Paz", en Diplomado Paz a la Acción, Colombia: Escuela Superior de Administración Pública.

ARN [Agencia para la Reincorporación y la Normalización] (2019), "ARN Bajo Magdalena Medio", en Foro Construcción de Paz y Reconciliación, Colombia: Universidad Cooperativa de Colombia.

Bouvier, Virginia (2014), "Innovative Approaches in the Colombian Peace Process", en Mediation Perspectives, Suiza: Center for Security Studies.

Bouvier, Virginia (2016), El Género y el Papel de las Mujeres en el Proceso de Paz de Colombia, Estados Unidos: ONU Mujeres.

Bueno, María Angélica (2017), "Políticas públicas de reconciliación: Un reto posible en la construcción y la sostenibilidad de la paz en Colombia”, en Análisis Político, núm. 90, Colombia: Universidad Nacional de Colombia.

Cairo, Heriberto et al. (2018), “Territorial Peace': The Emergence of a Concept in Colombia’s Peace Negotiations”, en Geopolitics, vol. 23, núm. 2, Inglaterra: Taylor and Francis. DOI: 10.1080/14650045.2018.1425110 Disponible en: https://doi.org/10. 1080/14650045.2018.1425110 [4 de julio de 2019].

Carta a una Sombra (2015), Documental, directores: Daniela Abad y Miguel Salazar, Colombia: Producciones La Esperanza y Caracol Televisión.

CEV [Comisión de la Verdad] (2019a), 21 claves para conocer a la Comisión de la Verdad, Colombia: Comisión de la Verdad. Disponible en: https://comisiondelaverdad.co/ participe/preguntas-frecuentes [4 de julio de 2019].

CEV [Comisión de la Verdad] (2019b), Lineamientos Metodológicos Escuchar, Reconocer, y Comprender Para Transformar, Colombia: Comisión de la Verdad. Disponible en: https://comisiondelaverdad.co/images/zoo/publicaciones/archivos/comisionverdad-lineamientos-metodologicos-2019-01-18.pdf [ 4 de julio de 2019].

CEV [Comisión de la Verdad] (2019c), Cuatro preguntas clave para entender el papel del arte y la cultura en la comprensión del conflicto, Colombia: Comisión de la Verdad. 
Disponible en: https://comisiondelaverdad.co/actualidad/noticias/cuatro-preguntasclave-para-entender-el-papel-del-arte-y-la-cultura-en-la-comprension-del-conflictoarmado [ 4 de julio de 2019].

CNMH [Centro Nacional de Memoria Histórica] (2013), ;Basta ya! Colombia: Memorias de guerra y dignidad, Colombia: Centro Nacional de Memoria Histórica.

Comins, Irene (2015), "De víctimas a sobrevivientes: la fuerza poiética y resiliente del cuidar", en Convergencia Revista de Ciencias Sociales, núm. 67, México: Universidad Autónoma del Estado de México. DOI: 10.29101/crcs.v0i67.2181 Disponible en: https://doi.org/10.29101/crcs.v0i67.2181 [4 de julio de 2019].

Cremin, Hilary y Archer, Tim (2018), "Transrational Education: Exploring Possibilities for Learning About Peace, Harmony, Justice and Truth in the Twenty First Century", en Echavarría, Josefina et al. [eds.], Transrational Resonances: Echoes to the Many Peaces, Inglaterra: Palgrave Macmillan.

Daşl1, Güneş et al. (2018), Peace and Gender: The Colombian Peace Process, Turquía: Research Center for Peace, Democracy and Alternative Politics.

Defensoría del Pueblo (2019), Homicidios de Lideres Sociales y Defensores de Derechos Humanos, Colombia: Defensoría del Pueblo. Disponible en: http://www.defensoria. gov.co/es/public/contenido/7399/Homicidios-de-1\%C3\%ADderes-sociales-ydefensores-de-DDHH.htm [ 4 de julio de 2019].

Dietrich, Wolfgang (2012), Interpretations of Peace in History and Culture, Inglaterra: Palgrave Macmillan.

Dietrich, Wolfgang (2013), Elicitive Conflict Transformation and the Transrational Turn in Peace Politics, Inglaterra: Palgrave Macmillan.

Dietrich, Wolfgang (2017), Elicitive Conflict Mapping, Inglaterra: Palgrave Macmillan.

Du Toit, Faine (2018), When Political Transitions Work: Reconciliation as Interdependence, Estados Unidos: Oxford University Press.

Echavarría, Josefina (2010), In/Security in Colombia: Writing Political Identities in the Democratic Security Policy, Inglaterra: Manchester University Press.

Echavarría, Josefina (2015), "Die Kunst des Social Healing in Kolumbien", en Polylog: Zeitschrift für interkulturelles Philosophieren, núm. 34, Viena: Wiener Gessellschaft für Interkulturelle Philosophie.

Echavarría, Josefina (inédito), Diario de Investigación.

Echavarría, Josefina et al. (2019), Wablen und Weichenstellungen in Lateinamerika 2018: Eine länderspezifische Analyse, Austria: Universidad de Viena e Instituto Austriaco para América Latina.

Enslin, Penny y Ramírez-Hurtado, Carmen (2013), "Artistic Education and the Possibilities for Citizenship Education", en Citizenship, Social and Economics Education, vol. 12, núm. 2, Inglaterra: Sage.

Escobar, Arturo (2014), Sentipensar con la tierra: nuevas lecturas sobre desarrollo, territorio $y$ diferencia, Colombia: Ediciones Universidad Autónoma Latinoamericana (UNAULA).

Forastelli, Fabricio (2015), "Filosofía para hacer las paces: un esbozo biográfico-intelectual de Vicent Martínez Guzmán”, en Revista Interdisciplinar de Direitos Humanos, núm. 4, Brasil: Observatório de Educação em Direitos Humanos.

Fundación Pares (2018), Cómo va la paz: La reestructuración unilateral del Acuerdo de Paz, Colombia: Fundación Pares. Disponible en: https://pares.com.co/2018/11/27/ como-va-la-paz-la-reestructuracion-unilateral-del-acuerdo-de-paz/ $[4$ de julio de 
2019].

Goebertus, Juanita (2016), "Víctimas”, en Diplomado Paz a la Acción, Colombia: Escuela Superior de Administración Pública.

Gomez-Suárez, Andrei (2017), "Peace Process Pedagogy: lessons from the no-vote victory in the Colombian peace referendum", en Comparative Education, vol. 53, núm. 3. DOI: 10.1080/03050068.2017.1334425 Disponible en: https://doi.org/10.1080/0 3050068.2017.1334425 [4 de julio de 2019].

Hancock, Landon y Mitchell, Christopher [eds.] (2007), Zones of Peace, Estados Unidos: Kumarian Press.

Hernández, Esperanza (2019), Del limbo al acuerdo final de paz. El proceso de paz entre el Gobierno Santos y las Farc-EP, Colombia: Universidad Autónoma de Bucaramanga.

Hernández, Esperanza [ed.] (2018), Educación para la Paz y Procesos de Paz, Colombia: Universidad de la Salle.

Jaramillo, Sergio (2016), "Prólogo: La Imaginación para la Paz", en Lederach, John Paul, La Imaginación Moral, Colombia: Semana Libros.

JEP [Jurisdicción Especial para la Paz] (2019), "Jurisdicción Especial para la Paz". Disponible en: https://www.jep.gov.co/Paginas/JEP/Jurisdiccion-Especial-para-la-Paz.aspx [4 de julio de 2019].

Jiménez Robles, Juan Manuel (2016), “On Forgiveness and Reconciliation in post-conflict societies: A Philosophical Perspective”, en Revista Interdisciplinar de Direitos Humanos, vol. 4, núm. 2, Brasil: Observatório de Educação em Direitos Humanos.

Koppensteiner, Norbert (2018), "Transrational Methods of Peace Research: The Researcher as (Re)source”, en Echavarría, Josefina et al. [eds.], Transrational Resonances: Echoes to the Many Peaces, Inglaterra: Palgrave Macmillan.

Kroc Institute (2018), Second Kroc Institute Report Shows Steady Progress of Peace Accord Implementation in Colombia, Colombia: Kroc Institute for International Peace Studies. Disponible en: https://kroc.nd.edu/news-events/news/second-kroc-institute-reportshows-steady-progress-of-peace-accord-implementation-in-colombia/ [ 4 de julio de 2019].

Lederach, John Paul (1995), Preparing for Peace: Conflict Transformation Across Cultures, Estados Unidos: Syracuse University Press.

Lederach, John Paul (2016), La Imaginación Moral: El arte y el Alma de la Construcción de la Paz, Colombia: Semana Libros.

Lederach, John Paul y Lederach, Angela Jill (2014), Cuando la Sangra y los Huesos Claman: Travesias por el paisaje sonoro de la curación y la reconciliación, País Vasco: Asociación de Investigación por la Paz Gernika Gogoratuz.

Leiner, Martin y Flämig, Susan (2012), "Reconciliation in the Middle of Dispute", en Leiner, Martin y Flämig, Susan [eds.], Latin America between Conflict and Reconciliation, Alemania: Vandenhoeck \& Ruprecht.

Martínez Guzmán, Vicent (2001), Filosofía para hacer las paces, España: Icaria.

Martínez Guzmán, Vicent (2005), Podemos Hacer las Paces. Reflexiones éticas tras el 11-Sy el 11-M, España: Desclée de Brouwer.

Martínez Guzmán, Vicent et al. (2009), "La nueva agenda de la filosofía para el siglo XXI: los estudios para la paz”, en Convergencia, Revista de Ciencias Sociales, número especial de aniversario IA, México: Universidad Autónoma del Estado de México. 
Más Arte, Más Paz (2019), “Calendario 2019”, Colombia: Más Arte, Más Paz.

Mouly, Cecile y Hernández, Esperanza [eds.] (2019), Civil Resistance and Violent Conflict in Latin America. Mobilizing for Rights, Inglaterra: Palgrave Macmillan.

Muñoz, Francisco (2006), "La Paz Imperfecta en un Universo en Conflicto", en Dietrich, Wolfgang et al. [comps.], Schlüsseltexte der Friedensforschung/Key Texts of Peace Studies / Textos Claves de la Investigación para la Paz, Austria: Lit.

Murphy, Jenny (2018), “Elephant Watering (W)hole: Transrational Learning Spaces”, en Echavarría, Josefina et al. [eds.], Transrational Resonances: Echoes to the Many Peaces, Inglaterra: Palgrave Macmillan.

Museo Nacional de Colombia (2019), Fragmentos: Espacio de Arte y Memoria, Colombia: Museo Nacional de Colombia. Disponible en: http://www.museonacional.gov.co/ micrositios1/Fragmentos/index.html\#section-practicing-areas [4 de julio de 2019].

Paffenholz, Thania (2015), "Unpacking the local turn in peacebuilding: a critical assessment towards an agenda for future research", en Third World Quarterly, vol. 36, núm. 5, Inglaterra: Taylor and Francis. DOI: 10.1080/01436597.2015.1029908 Disponible en: https://doi.org/10.1080/01436597.2015.1029908 [4 de julio de 2019].

Paris-Albert, Sonia (2017), "Filosofía para hacer las paces con niñas y niños. Un estímulo para la creatividad”, en Convergencia Revista de Ciencias Sociales, núm. 75, México: Universidad Autónoma del Estado de México.

Peace Insight (2017), Understanding the implementation of the Colombian peace agreement: the Kroc Institute Report, Inglaterra: Peace Direct.

Peña, Luis (2019), "Paz Territorial: Conectando Imaginación Moral e Imaginación Geográfica”, en Working Papers CAPAZ, núm. 5, Colombia: CAPAZ Instituto Colombo-Alemán para la Paz.

Rettberg, Angelika y Ugarriza, Juan (2016), "Reconciliation: A comprehensive framework for empirical analysis", en Security Dialogue, vol. 6, núm. 47. DOI: 10.1177/0967010616671858 Diponible en: https://doi. org/10.1177\%2F0967010616671858 [4 de julio de 2019].

Salcedo, Doris (2018), "Una Polifonía de Voces", en Revista Arcadia, Colombia: Publicaciones Semana.

Sánchez, Gonzalo (2019), "La guerra en tres actos”, en Semana Online. Disponible en: https://www.semana.com/opinion/articulo/la-guerra-en-tres-actos-columna-degonzalo-sanchez/619401\# [4 de julio de 2019].

Semana (2019), "Jesús Abad Colorado inaugura 'El testigo', su exposición más ambiciosa”, en Semana Online. Disponible en: https://www.semana.com/cultura/articulo/ jesus-abad-colorado-inaugura-su-exposicion-el-testigo-en-el-museo-claustro-de-sanagustin/587578 [4 de julio de 2019].

Sierra, Yolanda (2019), "Yolanda Sierra: "El arte y la cultura contribuyen a la justicia restaurativa”, en El Espectador, Colombia. Disponible en: https://www.elespectador. $\mathrm{com} /$ colombia2020/justicia/jep/yolanda-sierra-el-arte-y-la-cultura-contribuyen-lajusticia-restaurativa-articulo-857844 [ 4 de julio de 2019].

The Smiling Lombana (2018), Documental, directora Daniela Abad, Colombia: Producciones La Esperanza.

UBPD [Unidad de Búsqueda de Personas Dadas por Desaparecidas] (2019a), "Acerca de la UBPD”. Disponible en: https://www.ubpdbusquedadesaparecidos.co/acerca-de-labusqueda/ [4 de julio de 2019]. 
UBPD [Unidad de Búsqueda de Personas Dadas por Desaparecidas] (2019b), "Pedagogía". Disponible en: https://www.ubpdbusquedadesaparecidos.co/pedagogia/ [ 4 de julio de 2019].

Universidad Nacional de Colombia (2019), "El Testigo: Memorias del conflicto armado colombiano en el lente y la voz de Jesús Abad Colorado". Disponible en: http:// patrimoniocultural.bogota.unal.edu.co/eventos/article/el-testigo-memorias-delconflicto-armado-colombiano-en-el-lente-y-la-voz-de-jesus-abad-colorado.html [ 4 de julio de 2019].

Josefina Echavarría Álvarez. Doctora en Paz, Conflictos y Democracia por la Universitat Jaume I de Castellón, España. Co-Directora del Centro de Investigación de Paz y Conflictos InnPeace de la Universidad de Innsbruck, Austria. Profesora Visitante en el Instituto Kroc de Estudios Internacionales de Paz, Universidad de Notre Dame, Estados Unidos. Líneas de Investigación: reconciliación, educación y construcción de paz; subjetividad, migración e (in)seguridad; análisis y mapeo elicitivo de conflictos; género y paz. Publicaciones recientes: Echavarría Álvarez, Josefina y Koppensteiner, Norbert (2019), Mediation und Elizitive Konflikttransformation, Alemania: Verlag Österreich; Echavarría Álvarez, Josefina and Cremin, Hilary (2019), "Education for territorial peace in Colombia: What role for transrational peace?”, en Journal of Peace Education, Inglaterra: Taylor \& Francis; Echavarría Álvarez, Josefina y Rojas, Erika Julieta (2018), "Sexualidad y reconocimiento como apuestas a la transformación de la seguritización en El Salvador: una reflexión transracional", en Organicom, vol. 15, núm. 28, Brasil: Universidade de Sao Pablo/ Gestcorp. 